\title{
Determinantes de la pobreza extrema en España desde una doble perspectiva: Monetaria y de privación
}

\author{
MARÍA GIL IZQUIERDO y SALVADOR ORTIZ SERRANO \\ Facultad de CC. Económicas y Empresariales \\ UNIVERSIDAD AUTÓNOMA DE MADRID \\ e-mail: maria.gil@uam.es
}

\section{RESUMEN}

\begin{abstract}
Los cambios experimentados por la sociedad española en las últimas décadas pueden haber modificado la distribución de la renta y el perfil de pobreza en nuestro país. El presente trabajo tiene como principal objetivo retomar el análisis de los factores socioeconómicos que determinan las situaciones de pobreza extrema en el nuevo milenio. Utilizando algunos indicadores monetarios tradicionales para la medición de la pobreza, los resultados demuestran que existen ciertos factores que perduran en el tiempo como determinantes de la pobreza extrema, mientras que otras variables han modificado su impacto. Esta visión monetaria de la pobreza se completa con un estudio de la misma desde un punto de vista de privación, comprobándose que, cuando se adopta un enfoque multidimensional, algunos de los factores que determinan la pobreza extrema cambian su efecto.
\end{abstract}

Palabras clave: Pobreza extrema, privación, Encuesta de Condiciones de Vida, modelos de elección discreta.

\section{Severe Poverty Determinants in Spain Using Both a Monetary and a Deprivation Approach}

\begin{abstract}
Changes in Spanish society in last decades may have modified the income distribution and the poverty profile in our country. The main aim of this paper is to bring up to date the analysis of socioeconomic factors determining situations of severe poverty in the new millennium. Using some of the traditional monetary indexes for poverty measuring, results show the prevalence in time of several factors as determinants of severe poverty, whereas some other variables have modified their impact. This monetary vision of poverty is completed using a deprivation poverty approach; we may conclude that when a multidimensional approach is adopted, some of the factors determining severe poverty have a different effect.
\end{abstract}

Keywords: Severe Poverty, Deprivation, Discrete Choice Models, EU-SILC (European Union Statistics on Income and Living Conditions).

Clasificación JEL: C25, D63, I32.

Artículo recibido en julio de 2008 y aceptado en noviembre de 2008.

Artículo disponible en versión electrónica en la página www.revista-eea.net, ref. ə-27201. 


\section{INTRODUCCIÓN}

El estudio de la pobreza ha adquirido en los últimos años una gran importancia en el marco de los análisis económicos y sociales, consolidándose como una línea de investigación que tiene ya entidad propia. El interés de los gobiernos por conocer la situación de los hogares e individuos más desfavorecidos se sustenta en el deseo de desarrollar políticas eficaces para la reducción de los desequilibrios existentes, así como la búsqueda de una mayor justicia social. En este sentido, las investigaciones acerca de las condiciones de vida y de la exclusión social de una determinada población tienen un papel cada vez más relevante. Para el caso español, la publicación en épocas recientes de nuevas bases de microdatos que recogen estas cuestiones permite actualizar este tipo de trabajos, a la vez que abre la posibilidad de aproximarse al estudio de la pobreza desde diferentes perspectivas.

El objetivo fundamental de este trabajo consiste en analizar, de forma detallada y desde diferentes aproximaciones, cuál ha sido la evolución experimentada en el perfil de los hogares españoles que se encuentran en una situación de pobreza extrema, desde principios de los años noventa hasta el comienzo del nuevo milenio. Existen varios argumentos que justifican el interés de este trabajo: por una parte, los cambios en ciertas características socioeconómicas que la sociedad española ha experimentado en los últimos años justifican retomar esta línea de investigación, de tal forma que se pueda constatar si estos cambios han modificado también los determinantes de la pobreza en nuestro país. Por otra parte, nos centramos en una definición concreta de la pobreza, la pobreza extrema, para la que no existen muchos resultados de estudios previos, pero que cuenta con un gran interés económico y social por fijarse en el bienestar de los ciudadanos más desfavorecidos. Finalmente, somos conscientes de que existen diferentes métodos para aproximarse al análisis económico de la pobreza, cada uno de los cuales cuenta con ventajas y limitaciones, sin que exista un consenso unánime sobre cuál es la metodología más adecuada para realizar dicho análisis. Así, si bien la concepción monetaria de la pobreza ha sido la que utilizada en la mayoría de estudios para el caso español (centrada en los hogares o individuos con bajos recursos monetarios), existe un menor número de ellos que considere aspectos multidimensionales de la pobreza, esto es, que se centre en la privación. Esta última visión de la pobreza permite abarcar aspectos de la misma que no pueden ser tenidos en cuenta con único indicador monetario, ya que éstos no miden si los ciudadanos tienen cubiertas sus necesidades de determinados bienes y servicios básicos.

Por todo lo anterior, el valor añadido de este trabajo se puede concretar en dos tipos de propuestas: en primer lugar, en la actualización del análisis sobre los factores que determinan la pobreza extrema de los ciudadanos españoles, estudiando cómo han evolucionado éstos desde comienzo de los años noventa. Para ello, se propone el uso de la Encuesta de Condiciones de Vida para el año 2004, puesto que la información que presenta la hace especialmente adecuada para nuestros objetivos. Y en segundo lugar, se quiere ofrecer un doble estudio de los determinan- 
tes de la pobreza, utilizando dos tipos de indicadores aplicados a la misma población: monetarios y de privación. Esto nos permitirá obtener resultados complementarios, y lo que es más importante, verificar si existen diferencias importantes en la determinación de la pobreza extrema bajo una u otra aproximación.

\section{UNA APROXIMACIÓN MONETARIA AL ESTUDIO DE LA POBREZA: METODOLOGÍA Y DATOS}

El estudio de la pobreza desde una perspectiva estadística puede realizarse a partir de diferentes aproximaciones. A lo largo del tiempo se han producido avances metodológicos que han supuesto una clara mejoría en la medición económica de la pobreza, aunque siguen existiendo una serie de aspectos sobre los que el investigador debe realizar diversas decisiones, las cuales pueden condicionar los resultados que se obtengan. Estas decisiones a adoptar (que en la mayoría de los casos se toman de manera arbitraria, ya que no existe consenso sobre cuál es la mejor elección) se refieren a la elección del indicador de bienestar, a la determinación de la línea de pobreza, a la decisión sobre el elemento objeto de estudio (hogares o individuos) y a la selección de uno o varios índices para evaluar la pobreza ${ }^{1}$.

A la hora de realizar cada una de estas fases de elección metodológica en el presente trabajo, hay que señalar que uno de los objetivos de éste es evaluar cómo han cambiado los determinantes de la pobreza en los últimos años. Por ello, se toma como referencia el trabajo de Ayala y Palacio (2000), en el que se analizan los determinantes de la pobreza extrema a partir de la Encuesta Básica de Presupuestos Familiares (EBPF) de 1990-912. Esto condiciona algunas de nuestras decisiones metodológicas, pero permite comparar de una manera homogénea (en la medida de lo posible), cuál ha sido la evolución de los determinantes de la pobreza extrema desde principios de los noventa hasta el año 2004. En nuestro caso se propone el uso de los microdatos de la Encuesta de Condiciones de Vida (ECV en adelante), la más reciente para el estudio de las condiciones de vida de la población española. Además, esta fuente de datos contempla un módulo exclusivo dedicado a la exclusión social. Por ello, esta fuente de información presenta una ventaja añadida y diferenciadora para el análisis económico de la pobreza en España en el nuevo milenio, frente a otras bases de datos.

Dado que las fases metodológicas de un análisis de pobreza monetario son ampliamente conocidas, a continuación se resumirán las decisiones concretas que se han adoptado en este trabajo. La primera cuestión, se refiere a la decisión acerca de

\footnotetext{
${ }^{1}$ Un estudio detallado en esta materia puede verse en Marco y Ortiz (2006) o en Cantó, et al. (2000).

${ }^{2}$ Somos conscientes de que esta comparación ha de realizarse con cautela, puesto que los diseños metodológicos y las muestras seleccionadas en la EBPF (1990-91) y la ECV (2004) son diferentes. Además, la primera de ella recoge con gran detalle los gastos realizados por los hogares españoles, mientras que la segunda valora de forma mucho más ajustada los ingresos de dichos hogares y sus miembros.
} 
qué indicador utilizar para medir el bienestar de la población analizada. Para ello, la alternativa más frecuente desde un punto de vista empírico consiste en medir el bienestar, de manera indirecta, a partir de una variable monetaria ${ }^{3}$ que aproxime el poder adquisitivo de los hogares o individuos de dicha población. La elección de la ECV implica considerar como indicador del poder adquisitivo el ingreso total, puesto que se trata de la variable declarada por hogares e individuos en dicha encuesta.

En cuanto a la segunda decisión a adoptar, esto es, cuál es la línea de pobreza que se elige para determinar quién es considerado como pobre (por estar por debajo de ese umbral de renta), hay que tener en cuenta que nuestro análisis tiene como objetivo fundamental el estudio de la pobreza extrema. Por ello, se fija el $25 \%$ de los ingresos ${ }^{4}$ medios como línea de pobreza, siendo éste el porcentaje que, de manera general, se utiliza para analizar este tipo de pobreza. Esto nos permitirá asimismo evaluar cuál ha sido la evolución de la pobreza extrema en relación con los años noventa en España (Ayala y Palacio, 2000), con la cautela anteriormente mencionada.

Otra decisión importante, y no exenta tampoco de conflictos, es la elección de la unidad de análisis objeto de estudio: el hogar o el individuo ${ }^{5}$. Si bien la pobreza puede considerarse como un concepto esencialmente individual, la mayoría de las fuentes de información suministran datos sobre hogares, lo que hace que sea el hogar el elemento de referencia más utilizado en los estudios sobre la pobreza, y que será también la unidad de análisis elegida en nuestro estudio. No obstante, el uso de los hogares implica tener en consideración las diferencias de necesidades entre los individuos pertenecientes al hogar, las economías de escala que se producen dentro del hogar y cómo se distribuyen los recursos entre sus distintos miembros. En este punto entran en juego las escalas de equivalencia, cuyo objetivo es llevar a cabo una normalización que permita el análisis comparativo de hogares de distinto tamaño y composición. De todas las escalas disponibles a nivel teórico, es la escala de la OCDE modificada (adoptada por Eurostat ${ }^{6}$ ) es ampliamente utilizada, y es la que se ha elegido en este trabajo. De nuevo, esta decisión está motivada por el deseo de comparar, en la medida de lo posible, nuestros resultados con los de trabajos previos.

\footnotetext{
${ }^{3}$ Hay que señalar que en los análisis de distribución y redistribución de renta se suele realizar, de manera casi automática, una aproximación casi exacta entre renta y bienestar, bajo la creencia de que al igualar las rentas de los individuos estamos igualando su bienestar, lo cual sólo es cierto bajo ciertas condiciones muy restrictivas, detalladas en Zubiri (1985): rentas exógenas, preferencias iguales, utilidades lineales en renta, e índices de desigualdad homogéneos de grado cero.

${ }^{4} \mathrm{Se}$ consideran los ingresos totales netos de los hogares (véase su definición en la metodología de la ECV, 2004), los cuales constituyen la unidad de análisis seleccionada, como se indica en el siguiente párrafo.

${ }^{5}$ Hay que tener presente que la ECV, al dirigirse únicamente a individuos que viven en hogares, no recoge información de personas sin hogar o que viven en hogares colectivos que, presumiblemente se encuentran en situación de pobreza extrema.

${ }^{6}$ Esta escala determina el tamaño equivalente de un hogar ponderando a cada miembro del hogar de la siguiente manera: asigna una ponderación de uno al primero de los adultos del hogar, el resto de adultos del hogar se pondera con 0,5 y los niños quedan ponderados por 0,3 (Eurostat, 2002).
} 
La última de las decisiones, desde esta aproximación monetaria al concepto de pobreza, se refiere a los índices que miden las distintas dimensiones de la pobreza. En este sentido, la literatura proporciona gran variedad de medidas que permiten analizar tales dimensiones. En este trabajo se utilizan la familia de índices de Foster, Greer y Thorbecke (1984) ${ }^{7}$, con parámetros de aversión a la desigualdad 0, 1 y 2, lo que permite medir la incidencia, intensidad y desigualdad de la pobreza. Dichos índices quedan definidos a partir de la siguiente expresión:

$$
F G T_{\alpha}(y ; z)=\frac{1}{n} \sum_{i=1}^{q}\left[\frac{z-y_{i}}{z}\right]^{\alpha}, \alpha>1,
$$

donde $y$ indica la renta equivalente del hogar, $z$ es el umbral de pobreza, $q$ es el número de hogares pobres y es el parámetro de aversión a la desigualdad. Según el valor de se obtienen distintos índices. A mayores valores de más importancia relativa se le da a los desniveles de pobreza relativa mayores. También se puede comprobar que para . igual a cero, el índice muestra la proporción de pobres ${ }^{8}$; para igual a uno el índice es igual al producto de la proporción de pobres por el desnivel de pobreza ${ }^{9}$; mientras que para un valor de. igual a dos el índice es:

$$
F G T_{2}=H\left[I^{2}+(1-I)^{2} C V_{p}^{2}\right]
$$

Como se observa, incorpora un índice de desigualdad en el índice de pobreza (el coeficiente de variación de Pearson $\left(C V_{p}\right)$ ), recogiendo, de esta manera, ese aspecto de la pobreza.

\section{CARACTERÍSTICAS SOCIOECONÓMICAS DE LOS HOGARES EN 2004: EVOLUCIÓN RESPECTO A LOS AÑOS 90 Y EXTENSIÓN A LOS HOGARES POBRES}

Como ya se ha comentado, uno de los objetivos de este trabajo es el de analizar la evolución de la pobreza (siguiendo las decisiones metodológicas apuntadas en el apartado anterior), con el fin de comprobar si los factores que determinan las situaciones de pobreza de los hogares han cambiado desde la década de los noventa hasta el comienzo del nuevo milenio. En este epígrafe estaremos interesados, en primer lugar, en describir cuál ha sido la evolución experimentada en ciertas carac-

\footnotetext{
${ }^{7}$ Estos índices son utilizados en Martín-Guzmán et al. (1996) y Cantó et al. (2003), entre otros.

${ }^{8} H=\frac{q}{n}$, donde $q$ es el número de pobres y $n$ el total de elementos.

${ }^{9} F G T_{1}=H I ; \quad I=\frac{\sum_{i=1}^{n}\left(\frac{z-y_{i}}{z}\right)}{q}$ donde $I$ es el desnivel de pobreza, $z$ es el umbral de pobreza e $y_{i}$ es la renta del individuo $i$-ésimo.
} 
terísticas socioeconómicas de los hogares y de sus sustentadores principales entre 1990 y 2004. Posteriormente, se ofrecen algunos índices — para esas mismas características socioeconómicas - que miden la incidencia, la intensidad y la desigualdad de la pobreza en el año 2004.

\subsection{Comparativa del perfil de los hogares españoles en 2004 y en 1990}

El objetivo de este apartado es el de constatar si en los últimos quince años ha cambiado sustancialmente el perfil de los hogares españoles, en relación a ciertas características sociodemográficas, ya que esto puede provocar cambios en los factores que determinan las situaciones de pobreza. En el Cuadro 1 (Anexo) se representa la distribución de frecuencias relativas para los hogares según ciertas variables relativas al origen socioeconómico de dichos hogares, para los dos periodos analizados. En ellos aún no se abordan cuestiones relativas a la pobreza, sino que se pretende describir la evolución, en términos generales, de ciertas condiciones de vida de la población española en la última década, y ofrecer así una panorámica de los cambios recientemente acaecidos en sus hogares. Para facilitar esta comparación, se han homogeneizado, en la medida de lo posible, las variables objeto de estudio para ambos periodos ${ }^{10}$. Hay que señalar sin embargo, que algunas de las variables creadas en ambas bases de datos proceden de definiciones que pueden diferir en ambas encuestas, como se verá en los párrafos siguientes ${ }^{11}$. Además, en la ECV se identifica como sustentador principal al principal responsable de la vivienda a aquel miembro del hogar a cuyo nombre esté el título de propiedad o el contrato de arrendamiento o subarrendamiento de la vivienda. Por el contrario, en la EBPF el sustentador principal es aquel miembro del hogar, habitualmente presente en el mismo, cuya aportación periódica (no ocasional) al presupuesto común, se destina a atender los gastos del hogar en mayor grado que las aportaciones de cada uno de los restantes miembros.

En el Cuadro 1 (Anexo) se aprecia cómo ha cambiado el perfil de los sustentadores principales según su sexo y edad. A pesar de que tanto a principios de los noventa como en el año 2004 predominan los hogares sustentados por hombres, se observa un aumento nada despreciable en la proporción de hogares sustentados por mujeres, sobre todo, mayores de 30 años El creciente aumento de hogares monoparentales (como se verá en párrafos posteriores) puede apuntarse como una de las causas más plausibles de este cambio en el perfil de los sustentadores de los hogares en nuestro país ${ }^{12}$. Otro de los aspectos clave que todos los estudios sobre po-

\footnotetext{
${ }^{10}$ A pesar de ello, conviene recordar que ambas bases de datos proceden de diseños de encuestas y de muestras distintas, por lo que las comparaciones han de realizarse con cautela.

${ }^{11}$ Para una definición exacta de la definición y construcción de cada una de las variables presentadas en el Cuadro 1, véanse las metodologías de la ECV (2004) y EBPF (1990-91).

12 El incremento del número de disoluciones del matrimonio que se ha producido en estas décadas (con un incremento en el número de separaciones, divorcios y nulidades del 89,3\%, entre 1991 y 2003 según datos de la Memoria del Consejo General del Poder Judicial) puede ser una de las causas del aumento en el número de hogares mantenidos por mujeres que tienen hijos a su cargo (el
} 
breza coinciden en señalar se refiere al nivel educativo máximo alcanzado por el sustentador principal. Los resultados indican que el cambio de cohortes ha conllevado una mejora en el stock de capital humano de los cabeza de familia en España a comienzos del nuevo siglo. Por el contrario, parece que el estatus laboral de los sustentadores principales de los hogares no ha cambiado de forma sustancial entre ambos periodos. Las mayores diferencias se observan en la categoría de inactivos, lo que se debe principalmente a la diferente categorización de ambas encuestas, más que a una evolución de dichas categorías. En relación a la tipología de hogares en función de su tamaño y composición, el cambio más apreciable es el aumento que se produce en el porcentaje de hogares unipersonales, que pasan de un $10 \%$ al $16 \%$ entre ambos años, y el descenso de los hogares formados por dos adultos con más de dos hijos a cargo. Aunque sin duda el aumento más relevante es el que experimentan los hogares monoparentales, esto es, hogares formados por un adulto y uno o más hijos a su cargo. A pesar de que suponen - junto con los hogares formados por dos adultos y más de dos hijos- los casos menos frecuentes, su incremento entre ambos periodos es de un $151 \%$, el más elevado de todas las tipologías. De forma similar, la distribución de hogares según su tamaño muestra la tendencia actual apunta hacia una importante reducción del tamaño de los hogares ${ }^{13}$, con el consiguiente aumento de los hogares con tres o menos miembros. Por último, se observa que apenas existen diferencias entre ambos periodos en la estructura ruralurbana en España, por lo que se puede decir que ésta apenas ha sufrido modificaciones en la última década.

\section{2. Índices de pobreza para los hogares españoles en 2004}

Una vez descrita la evolución del perfil socioeconómico de los hogares españoles, en este apartado estaremos en disposición de profundizar en el análisis de los factores asociados con situaciones de pobreza extrema en 2004, estudiando si éstos han cambiado respecto a décadas anteriores. Una de las formas habitualmente empleadas para abordar este estudio es el uso de índices calculados a partir de indicadores indirectos de tipo monetario, a través de los cuales se miden diferentes aspectos de la pobreza. En concreto, se propone el uso de algunos de los índices de la familia de Foster, Greer y Thorbecke (1984), con su formulación habitual ${ }^{14}$, vista en el epígrafe 2.

En el Cuadro 2 (Anexo) se recogen los resultados del cálculo de estos índices. Comenzando con las variables que se refieren al sexo y la edad del sustentador principal, se observa que los niveles de pobreza en todas sus dimensiones (incidencia, intensidad y desigualdad) aumentan cuanto más joven es el sustentador princi-

$30 \%$ del total de hogares están sustentados por mujeres mientras que esta proporción sube hasta el $87,5 \%$ cuando se trata de hogares monoparentales).

${ }^{13}$ En 2004 el tamaño medio de los hogares es de 2,86 miembros, frente a los 3,41 de 1990.

${ }^{14}$ Véanse Marco y Ortiz (2006) o Cantó, et al. (2000) para un estudio detallado de indicadores estadísticos para la medición de la pobreza. 
pal del hogar, y lo hacen en mayor medida si el sustentador es una mujer. En cuanto al nivel de estudios, se aprecian unos mayores niveles de pobreza, también en todas sus dimensiones, en aquellos hogares cuyo sustentador principal ha cursado estudios secundarios. Respecto a la situación laboral, los mayores niveles de pobreza, en todos sus aspectos, se observan en hogares cuyo sustentador principal está parado, seguidos de los hogares sustentados por trabajadores a tiempo parcial. A continuación, se situarían los hogares encabezados por inactivos (salvo jubilados) y por aquellos cuyos sustentadores principales trabajan a tiempo completo. Por último, como hogares con menores niveles de pobreza, se colocarían aquellos cuyo sustentador principal pertenece al colectivo de jubilados.

Centrándonos en las características de los hogares, si nos fijamos en su clasificación socioeconómica, se aprecia que los mayores niveles de pobreza se corresponden con hogares monoparentales, seguidos de los unipersonales y de aquéllos formados por una pareja con más de dos hijos. A continuación se sitúan las parejas uno o dos hijos y, por último, los hogares formados por parejas sin hijos, que constituyen los hogares con menores niveles de pobreza. En lo que se refiere al tamaño del hogar, no se pueden sacar conclusiones claras, salvo que los hogares con mayores niveles de pobreza son aquellos formados por más de seis miembros y los formados por un solo miembro. Sí parece clara la ordenación para la densidad de población del municipio de residencia del hogar. Para esta característica se aprecia que, a mayor densidad de población, menores niveles de pobreza en todas sus dimensiones.

Es decir, que los hogares sustentados por jóvenes, por desempleados o los hogares monoparentales son los que muestran una mayor intensidad, incidencia y desigualdad de la pobreza, mientras que los que cuentan con un sustentador pensionista parecen tener buenos resultados en estos indicadores. Todos estos aspectos han de tenerse en cuenta en el posterior análisis de pobreza y en su comparación con los resultados de años previos.

\section{DETERMINANTES DE SITUACIONES DE POBREZA EXTREMA EN EL NUEVO MILENIO}

Uno de los objetivos fundamentales que plantea este trabajo es el de caracterizar aquellos factores socioeconómicos que inciden en la probabilidad de que un hogar pueda caer en una situación de pobreza extrema a comienzos del siglo XXI, y evaluar cuál ha sido la evolución experimentada respecto a la década de los noventa. Recordemos que en este caso estamos interesados en una visión puramente monetaria de la pobreza, designando como hogares en situaciones de pobreza extrema a aquellos que tienen unos ingresos medios equivalentes inferiores al $25 \%$ de la renta media total española (menos de 2.921 euros equivalentes anuales ${ }^{15}$ ).

\footnotetext{
${ }^{15}$ Recordemos que se ha tomado como escala de equivalencia la de la OCDE modificada.
} 
Como es habitual en la literatura relacionada, en este trabajo se propone el uso de un modelo probabilístico de tipo probit (cuya variable dependiente toma el valor 1 en caso de que el hogar se encuentre en una situación de pobreza extrema y 0 en caso contrario), utilizando para ello el programa informático Stata. La estimación se ha realizado utilizando el método de máxima verosimilitud. En concreto, se proponen cuatro modelos alternativos al objeto de evitar los problemas de multicolinealidad que presentan algunas de las variables independientes empleadas. De esta manera se evita introducir en un mismo modelo variables explicativas que se encuentren altamente relacionadas, lo que provocaría problemas en la estimación. Como se pone de manifiesto en el Cuadro 3 (Anexo), las variables que se refieren a la percepción de transferencias y salarios están muy asociadas con la variable referida al estatus laboral; esto mismo ocurre con el tamaño del hogar y la tipología del mismo, lo que indicaría la necesidad de que no coincidan estas variables tan relacionadas en un mismo modelo.

Los modelos especificados recogen como variables independientes algunas referidas al hogar estrictamente, como son la tipología y tamaño del hogar, la zona o región de residencia y el hecho de que existan o no perceptores de transferencias públicas o salarios en el hogar; por otra parte, existen variables propias del sustentador principal, como es su edad y sexo, nivel de estudios y estatus laboral ${ }^{16}$.

Los resultados de las regresiones realizadas para una muestra final de 13.180 hogares ${ }^{17}$ se recogen en el Cuadro 4 (Anexo). El test de razón de verosimilitud indica que las variables especificadas son significativas en conjunto. Los resultados que se proporcionan son robustos a la heteroscedasticidad ${ }^{18}$. Los porcentajes de predicciones correctas son diferentes para los dos valores de la variable explicada, y se especifican en las dos últimas filas del Cuadro 4 (Anexo). Para calcular estos porcentajes se toma como punto de corte el porcentaje de hogares en una situación de pobreza extrema ${ }^{19}(3,28 \%)$. Los coeficientes de las variables proporcionados son interpretables en términos de su efecto marginal, es decir, en términos de la variación en la probabilidad de ser pobre que se produce al considerar un cambio en la variable tomada como referencia en cada caso, manteniendo el resto constantes.

Comenzando con las características demográficas del sustentador principal de los hogares españoles, se observa una mayor incidencia de la pobreza extrema en

\footnotetext{
${ }^{16}$ Hay que señalar que para la selección de estas variables independientes se ha seguido estrechamente la realizada en Ayala y Palacio (2000) para cumplir con el objetivo de analizar la evolución que se ha producido entre los periodos de análisis que muestran ambos estudios.

${ }^{17}$ La muestra inicial de hogares que proporciona la ECV es de 15.355 hogares en el año 2004. Sin embargo, la existencia de missing values en algunas variables utilizadas en nuestro análisis, hace que el número de hogares que finalmente pueden incluirse en los modelos de regresión sea de 13.180 hogares.

${ }^{18}$ En concreto, las estimaciones se realizan utilizando el estimador de Huber-White en el cálculo de la matriz de varianzas y covarianzas.

${ }^{19}$ Las razones estadísticas para adoptar esta decisión se explican con detalle en Green (1998), página 767.
} 
aquellos hogares con sustentadores jóvenes, que es significativa en la casi totalidad de los casos a nivel individual. Por el contrario, los mayores de 64 años parecen estar mejor protegidos contra esta situación, lo cual puede explicarse por la cobertura en términos de prestaciones públicas de que se beneficia este colectivo (pensiones por jubilación o viudedad y cobertura del sistema sanitario, sobre todo). Este resultado puede resultar contra intuitivo, ya que los resultados de muchos estudios señalan a los mayores como más proclives a sufrir diferentes formas de pobreza (Ayala, 2005). Sin embargo, hemos de recordar que se está empleando una definición monetaria de pobreza extrema, y es de este tipo de pobreza de la que parecen estar bien protegidos nuestros mayores. En relación a cuestiones de género, las mujeres tienen una probabilidad de tener bajos ingresos ligeramente inferior a los de los hombres, aunque las diferencias son mínimas. En relación a la educación, se comprueba que mayores niveles de formación disminuyen la probabilidad de tener unos ingresos reducidos, si bien su impacto en términos absolutos es menor que en el caso anterior (sexo y edad), observándose además que la educación secundaria de segunda etapa no arroja un impacto diferenciado respecto a la de primera etapa (siempre en comparación con la categoría de referencia, sin estudios o con estudios primarios). Si atendemos a la situación laboral del sustentador principal, trabajar a tiempo parcial o en labores del hogar, y sobre todo, estar desempleado, aumenta significativamente la probabilidad de que el hogar sea pobre. Las razones que pueden explicar este resultado son diversas: las prestaciones por jubilación aseguran unos ingresos fijos que son perdurables en el tiempo, mientras que las prestaciones por desempleo -y únicamente en caso de haberse generado el derecho a cobrarlas - , sólo cubren un determinado periodo de tiempo a sus beneficiarios. Además, debido a la etapa de ciclo vital en que normalmente se perciben estas últimas prestaciones, el ingreso equivalente de los hogares sustentados por un desempleado seguramente será más reducido que en el caso de un hogar encabezado por un pensionista (normalmente, unipersonal o pareja sin hijos). Por el contrario, el hecho de trabajar a tiempo completo o estar incapacitado parece no tener efectos significativamente diferentes en dicha probabilidad frente al hogar de referencia (cabeza de familia jubilado). El resultado relativo a la situación laboral de trabajo a tiempo completo puede resultar llamativo, puesto que señala que no existen diferencias significativas con el hecho de estar jubilado. Sin embargo, estos resultados son coherentes, por una parte, con el análisis univariante (Cuadro 2, Anexo), en el que se observa que son para los jubilados existe una menor incidencia de la pobreza extrema; y por otra, pueden deberse al concepto de pobreza utilizado (monetaria y pobreza extrema).

En relación con las características propias del hogar, se evalúa, en primer lugar, la incidencia en la pobreza extrema de la percepción de algún tipo de ingreso, ya sean transferencias públicas, ya sea algún salario percibido por al menos uno de los miembros del hogar. Los resultados muestran un impacto negativo y significativo en la probabilidad de ser pobre de ambos factores, superior en el caso de los salarios. Otro de los factores que tradicionalmente se analiza en el estudio de la pobre- 
za es el tamaño y la composición del hogar, cuyas categorías resultan ser significativas en casi todos los casos. En este sentido, llama la atención el hecho de que son los hogares monoparentales los únicos que aumentan la probabilidad de estar en una situación de pobreza extrema, frente a los unipersonales. Como se ha visto en el apartado descriptivo, el número de este tipo de hogares ha crecido notablemente en la última década, siendo además especialmente sensibles a situarse en situaciones de pobreza extrema ${ }^{20}$. Esto se debe a que en su mayoría son hogares formados por solteros $(50 \%)$ o bien derivados de la ruptura de una pareja a partir de la cual se forman un hogar monoparental - encabezado generalmente por una mujer con sus hijos (31,2\% de los hogares monoparentales) - y uno unipersonal (formado por el hombre). Esta duplicidad de hogares parece mermar los ingresos de ambos hogares. El resto de tipologías reducen esta probabilidad, sobre todo los recogidos bajo la denominación de "otros hogares". Si nos centramos únicamente en el tamaño, se observa que los hogares con más de un miembro son menos proclives a estar en una situación de pobreza. El tamaño elevado de los hogares también puede parecer a priori que implica un mayor riesgo en términos de pobreza, aunque en nuestros modelos la categoría de hogares con más de seis miembros aparece con signo contrario al esperado, si bien no es significativa. Esto puede deberse a la pequeña proporción que representan estos hogares en el total. Finalmente, y referido a cuestiones geográficas, se contempla la variable tamaño del municipio, a través de la que se demuestra que vivir en una zona con una densidad de población media o alta tiene un impacto reducido, pero positivo, en la probabilidad de que el hogar sea pobre.

\section{UNA APROXIMACIÓN AL ESTUDIO DE LA POBREZA DESDE UNA PERSPECTIVA DE PRIVACIÓN}

Hasta este punto, el análisis de la pobreza abordado en este trabajo se ha realizado desde un enfoque monetario, tomando como aproximación del bienestar de los hogares españoles un indicador monetario indirecto, en concreto, sus ingresos. Esta visión puramente monetaria cuenta con limitaciones, ya que sólo analiza la pobreza desde una de sus múltiples dimensiones. Desde una aproximación multidimensional de la pobreza, su estudio a partir de un solo indicador monetario parece no ser suficiente. Desde hace tiempo se aprecia un interés creciente en la literatura por ampliar las vías de análisis de la pobreza (Towsend, 1979, Mack y Lansley, 1985, Desai y Shah, 1988, Atkinson, 2003), proponiéndose para ello indicadores directos sobre las condiciones de vida (indicadores que denominaremos como de privación). Este tipo de indicadores están relacionados con el concepto de privación y analizan la pobreza desde una perspectiva multidimensional, ampliando el concep-

\footnotetext{
${ }^{20}$ Este tipo de hogares empeoran, si se compara su situación en el nuevo milenio con la que presentaban a principios de los noventa, como se comprueba en Ayala y Palacio (2000), Cuadro 5, página 53.
} 
to de pobreza y considerando otras dimensiones de la misma (acceso a bienes básicos para tener una vida digna, educación, salud, participación social, etc.). Así, la privación se convierte en un concepto más adecuado para identificar las situaciones de marginación en épocas más recientes.

\subsection{Privación: metodología}

En este epígrafe se pretende realizar un análisis del perfil de la pobreza similar al que se ha llevado a cabo en el apartado anterior, pero en este caso a partir de la utilización de indicadores de privación. De esta manera se podrá analizar las diferencias a la hora de estudiar la pobreza desde dos aproximaciones diferentes, complementando así los resultados y abarcando de esta manera una concepción global de la pobreza.

A pesar del interés a nivel teórico por medir la pobreza utilizando un concepto multidimensional, en la práctica, el uso de indicadores de privación ha sido poco frecuente, tanto a nivel internacional como para el caso de España ${ }^{21}$. Esto se debe a varias razones. Por un lado, la alternativa de los indicadores monetarios permite utilizar un gran número de diferentes índices de pobreza, lo que posibilita la realización de un análisis muy detallado de la pobreza, estudiando su incidencia, intensidad e incluso desigualdad dentro del colectivo de pobres. Por su parte, los indicadores de privación sólo permiten detectar la población que se puede considerar como pobre. Sin embargo, al hacerlo desde una perspectiva multidimensional, pueden proporcionar una mejor herramienta para detectar al colectivo de pobres de una sociedad. De hecho, la aplicación de este tipo de indicadores puede realizarse de manera complementaria junto con los indicadores monetarios ${ }^{22}$. Por otro lado, no existe un consenso sobre la metodología más adecuada a la hora de utilizar indicadores de privación de bienestar, lo que proporciona un gran abanico de posibilidades.

Al igual que en el caso de los indicadores monetarios, a la hora de enfrentarnos a esta aproximación del estudio de la pobreza, se deben tomar una serie de decisiones $^{23}$. La primera de ellas se refiere a la selección de los indicadores. No existe consenso sobre cuáles deben ser los indicadores a utilizar. Éstos pueden ceñirse sólo a aspectos materiales sobre las condiciones de vida o ampliarse a otros aspectos más extensos, como por ejemplo el acceso a la educación o al mercado laboral o a un buen estado de salud. Como solución a esta cuestión, los indicadores pueden centrarse en medir sólo los bienes y servicios básicos que son considerados como "necesarios" por una sociedad. Sin embargo, con ello surgen dos cuestiones: por

${ }^{21}$ En Bibi (2003) puede verse una revisión de la literatura sobre este tema. Para el caso español pueden consultarse los trabajos de Martín-Guzmán y Bellido (1994), Martínez y Ruiz Huerta (2000), Pérez-Mayo (2003), EDIS et al. (2003) y, muy recientemente, Ayllón et al. (2007).

${ }^{22}$ Un ejemplo puede verse en Martínez y Ruiz-Huerta (2000).

${ }^{23}$ Ver Martínez y Ruiz-Huerta (2000) para un estudio más detallado. En Bibi (2003) puede verse una revisión de la literatura sobre este tema. 
una parte, cómo determinar qué se considera necesario para poder clasificar a un hogar como pobre si éste no cuenta con esos bienes "necesarios", por otra, la posibilidad de atender a su vez a otros aspectos referentes al estilo de vida, sin que éstos tengan que ser considerados como estrictamente "necesarios" ${ }^{24}$. Para solventar esta situación en la selección de las variables, en este trabajo se ha decidido considerar todas las variables disponibles en el apartado de la ECV dedicado a la exclusión social, las cuales recogen aspectos relativos a si el hogar ha tenido algún impago o retraso en ciertas facturas, al equipamiento y condiciones de la vivienda y relacionadas con la percepción de si el hogar puede permitirse la realización de ciertos gastos (como vacaciones, imprevistos, consumo de ciertos alimentos, etc.).

Una vez seleccionados los indicadores de privación, se debe determinar cómo evaluar la privación a partir de ellos. Lo más común es generar variables dicotómicas a partir de las cuales se determine si se carece o no de un determinado bien o servicio. No obstante, esta manera de evaluar la privación deja de lado cierta información, ya que no tiene en cuenta, por ejemplo, ni la cantidad ni la calidad de los elementos a evaluar. Otra cuestión importante en la evaluación de la privación en los indicadores seleccionados es si ésta resulta o no forzada, es decir, si el hogar no accede a ese bien o servicio porque no dispone de suficientes recursos económicos, o si por el contrario no accede a ese bien o servicio porque así lo decide, aunque sí disponga de recursos suficientes. En nuestro trabajo se determina que se carece de un determinado bien o servicio sólo si esta carencia es debida a la falta de recursos.

El siguiente paso tiene como objetivo ponderar los diferentes indicadores. La ponderación de los mismos es crucial ya que permite dotar de mayor importancia a unos indicadores o a otros. Las alternativas son, básicamente, dos: se puede asignar la misma ponderación a todos los indicadores, o bien fijar ponderaciones distintas, atendiendo a algún criterio que muestre estas diferencias. Esto procede si se considera que es más importante, desde un punto de vista de la privación, carecer de unos determinados bienes y servicios que de otros. En este sentido existen dos alternativas: una, asignar ponderaciones de manera subjetiva, según crea la población que son más o menos importantes los indicadores elegidos; y otra, estableciendo la ponderación desde una perspectiva más objetiva, esto es, observando qué bienes y servicios son aquéllos de los que más carece la población (Desai y Shah, 1988). En este trabajo se ha optado por esta última opción. La importancia que se ha dado a cada uno de los indicadores se relaciona directamente con la proporción de población que no se ve privada de dicho indicador. De esta manera, desde un punto de vista de la privación, estará más desfavorecido aquel hogar que no disponga de un bien o servicio del que dispone la mayoría.

Una vez que se dispone de los distintos indicadores, la siguiente tarea consiste en agrupar éstos en uno o varios indicadores conjuntos. La agregación en un solo índice de privación puede provocar una pérdida de información multidimensional

\footnotetext{
${ }^{24}$ Ver Atkinson (2003) para un análisis detallado sobre indicadores de privación.
} 
sobre la pobreza, pero permite ganar en cuanto a tener una visión general sobre la misma. Por el contrario, si se agregan los indicadores en distintos índices conjuntos que muestren aspectos distintos de la pobreza (privación material, privación en cuanto a condiciones de la vivienda, privación en cuanto a estilo de vida, etc.) se puede analizar la pobreza desde un punto de vista multidimensional, a costa de no disponer de una visión global de la misma ${ }^{25}$. En este trabajo se ha optado por generar un único indicador conjunto de pobreza para analizar el problema desde una perspectiva global. La ventaja de este tipo de indicador conjunto de privación frente a la utilización de un indicador monetario como el ingreso-, es que a través de este último se dispone de información sobre a lo que podría acceder un hogar (en función de sus ingresos) mientras que a partir de la información directa se valora a qué bienes y servicios ha accedido realmente el hogar.

De las diferentes alternativas propuestas por la literatura, el indicador conjunto que se utiliza en este trabajo se define de la siguiente manera ${ }^{26}$ :

$$
P_{i}=\frac{\sum_{k} p_{i, k} w_{k}}{\sum_{k} w_{k}}
$$

donde,

$P_{i}$ es el valor del indicador conjunto de privación del hogar $i$-ésimo; $p_{i, k}$ es el valor del indicador de privación del hogar $i$-ésimo para la categoría $k$-ésima. Tomará el valor 1 si el hogar presenta privación en esa categoría y 0 si no la presenta; $w_{k}$ es la ponderación de la categoría $k$-ésima. Esta ponderación será igual a la proporción de hogares que no presenta privación en esa categoría.

Por último, hay que decidir cuál es el umbral de pobreza para el indicador seleccionado. La elección del umbral de pobreza cuando se trabaja con este tipo de indicadores no puede llevarse a cabo sin cierto grado de arbitrariedad. Una opción es tomar como pobres a aquéllos que presenten privación en una determinada proporción de indicadores; otra es tomar como pobres a una determinada proporción de la población con mayores niveles de privación ${ }^{27}$. En este trabajo se ha optado por esta última opción, de manera que se considera pobre al 3,3\% de los hogares con mayores niveles de privación ${ }^{28}$.

\footnotetext{
${ }^{25}$ Puede verse Bourguignon y Chackravarty (1998 y 2003) para un tratamiento más extenso sobre la pobreza multidimensional.

${ }^{26}$ Véase Desai y Shah (1988). Para un estudio de las propiedades de los índices de pobreza puede verse Bibi (2005).

${ }^{27}$ Ayllón y Mercader (2007) se decantan por esta opción.

${ }^{28}$ Éste es el porcentaje de pobres obtenido en el análisis de la pobreza con indicadores indirectos monetarios. Dado que en esta parte del estudio se pretende investigar las diferencias en el perfil de pobres determinados por ambas aproximaciones se ha considerado oportuno tomar un mismo porcentaje de hogares en situación de pobreza extrema en ambos análisis.
} 
Una vez calculado el indicador general de privación y detectados los hogares situados por encima ${ }^{29}$ de la línea de pobreza establecida, se han analizado las diferencias entre los hogares considerados pobres desde esta perspectiva, frente a los hogares pobres caracterizados en el epígrafe anterior, en que se empleaba una aproximación monetaria al estudio de la pobreza. El valor del coeficiente de correlación lineal entre el índice de privación y el ingreso equivalente $(-0,288)^{30}$, hace pensar que estas dos aproximaciones analizan aspectos de la pobreza diferentes, no necesariamente contrapuestos, sino complementarios. De hecho, se observa que menos del $15 \%$ de los hogares considerados como pobres coinciden en ambas definiciones.

\subsection{Determinantes de la pobreza extrema desde la perspectiva de la privación}

Para poder determinar hasta qué punto son diferentes los colectivos de pobres determinados por ambas metodologías, se han estimado cuatro modelos probit similares a los ajustados en el epígrafe anterior. Los resultados obtenidos al estimar los modelos se recogen en el Cuadro 5 (Anexo). Pasemos a comentar cada una de las variables analizadas incidiendo, fundamentalmente, en las diferencias respecto a los resultados obtenidos en los modelos ajustados en el apartado anterior.

En lo que se refiere a las variables relativas al sexo y la edad del sustentador principal, se mantiene, en general, la estructura observada en el epígrafe anterior, salvo en el caso de los hogares encabezados por mujeres menores de 30 años. Para este tipo de hogar se incrementa bastante la probabilidad de caer dentro del colectivo de privados respecto al resto de categorías. De hecho, pasa a ser la categoría con mayor probabilidad de ser pobre, dejando a los hogares sustentados por hombres menores de 30 años en la segunda posición. Respecto a la educación del sustentador principal, la ordenación es similar a la obtenida en los anteriores modelos, a mayor nivel educativo menor probabilidad de situarse dentro de una situación de privación. Hay que señalar que los hogares con sustentador principal con estudios secundarios de segundo ciclo presentan ahora menor probabilidad de caer en la pobreza que los de estudios secundarios de primer ciclo. En cuanto a la situación laboral del cabeza de familia, los cambios destacables en esta variable se refieren a la categoría de labores del hogar, que en este modelo no presenta diferencias significativas respecto al sustentador principal.

En relación al tipo de hogar, la diferencia más destacable es que los hogares monoparentales, aunque siguen siendo los que más probabilidad tienen de estar en situaciones de privación, disminuyen considerablemente esta probabilidad. Para el resto de categorías se reproduce una ordenación parecida: tras los hogares monoparentales se sitúan los hogares unipersonales como los de mayor probabilidad de

\footnotetext{
${ }^{29}$ Nótese que ahora a mayor privación mayor nivel de pobreza y, por tanto, los hogares pobres estarán por encima de la línea de pobreza.

${ }^{30}$ Este resultado es similar a los obtenidos en Martínez y Ruiz-Huerta (2000).
} 
estar en una situación de pobreza, a continuación se sitúan los hogares formados por una pareja con hijos y finalmente, los hogares sin hijos.

La densidad de población del municipio de residencia del hogar tiene un papel completamente distinto en esta nueva aproximación. Ahora, la mayor probabilidad de estar en situación de privación se presenta en los hogares situados en municipios más densamente poblados. Esto puede deberse a que, en los municipios más poblados, los ingresos de las familias son mayores (y por tanto la probabilidad de caer por debajo del umbral de pobreza es menor desde una aproximación monetaria) lo que no garantiza tener un nivel de privación menor. Parece lógico pensar que los hogares de estos municipios, con mayor densidad de población, deberán realizar unos desembolsos superiores para cubrir las mismas necesidades que en municipios de menor densidad (alquileres y precios de la vivienda más altos, mayores gastos de transporte, etc.).

Esto mismo ocurre con la percepción de transferencias. Para esta variable también cambia el efecto sobre la pobreza cuando se adopta una perspectiva de privación. En este caso, los hogares que reciben transferencias públicas aumentan la probabilidad de encontrarse en una situación de privación. Por el contrario, desde la aproximación monetaria, la percepción de este tipo de transferencias reducía la probabilidad de situarse bajo el umbral de pobreza extrema, ya que contribuía a que se incrementaran la renta disponible del hogar. Por tanto, parece que de este resultado se desprende que el hecho de recibir ayudas públicas (por enfermedad, minusvalía, viudedad, etc.) no evita, necesariamente, que los hogares puedan sufrir niveles altos de privación. Recibir una ayuda pública incrementa la renta del hogar, de manera que se puede situar fuera de la pobreza desde una perspectiva monetaria, sin embargo, esta mayor renta puede resultar insuficiente para paliar la privación que sufren los hogares que las reciben ya que, en muchas ocasiones, se dedicará a cubrir las necesidades derivadas de la situación que ha provocado la concesión de dicha ayuda.

No ocurre lo mismo con la percepción de salarios, variable que no modifica su efecto, de manera que se reproduce la situación de los modelos estimados anteriormente. Sin embargo, para el tamaño del hogar, la situación cambia por completo. En esta nueva aproximación no parece que sean significativas las diferencias del tamaño del hogar a la hora de determinar si éste es pobre. Por el contrario, los modelos ajustados a partir de indicadores monetarios mostraban que los hogares de mayor tamaño estaban más protegidos frente a situaciones de pobreza. Esto puede atribuirse al problema (de difícil solución) relativo al uso de las escalas de equivalencia, ya que la elección de una escala de equivalencia que valore de forma precisa las economías de escala dentro de los hogares resulta inalcanzable hoy por hoy. Los resultados obtenidos bajo esta visión monetaria parecen sobrevalorar las economías de escala por el uso de la escalas de equivalencia elegida (OCDE modificada). El estudio de la pobreza a partir de indicadores indirectos no presenta esta limitación ya que no precisa de escalas de equivalencia para poder comparar el bienestar de hogares de diferentes tamaños y composiciones. 
Como conclusión, puede decirse que bajo ambas aproximaciones (a partir de indicadores directos e indirectos), el perfil de los hogares situados en una posición de pobreza extrema es parecido. Sin embargo, existen algunas diferencias reseñables, que se comentan a continuación. Una serie de características de los hogares empeoran ${ }^{31}$ en cuanto a su efecto sobre la probabilidad de situarse en situación de pobreza cuando se analizan los determinantes de la pobreza extrema desde una perspectiva de privación con respecto al análisis desde una perspectiva monetaria. Esto indica que, para una serie de hogares, tener unos ingresos por encima del umbral de pobreza no les garantiza acceder a los bienes y servicios que la sociedad considera necesarios. En este sentido, los hogares encabezados por mujeres jóvenes presentan una mayor probabilidad de ser pobres en el análisis a partir de indicadores directos de privación; lo mismo ocurre con aquellos hogares que viven en municipios más densamente poblados y con aquéllos que perciben transferencias públicas. En estos dos últimos casos, cambia el efecto de estas variables por completo: vivir en un municipio más poblado disminuye la probabilidad de estar en una situación de pobreza extrema si tomamos como referencia un indicador monetario (como es el caso de los ingresos equivalentes), mientras que si consideramos indicadores de privación, vivir en municipios más densos incrementa esta probabilidad. De la misma manera, los hogares que reciben transferencias públicas tienen una menor probabilidad de estar en situación de pobreza extrema que aquéllos que no las reciben cuando se toma un indicador monetario y, sin embargo, incrementan esta probabilidad cuando se consideran indicadores de privación. En el otro extremo existen otra serie de características que mejoran la probabilidad de situar al hogar en una situación de pobreza cuando el análisis se realiza con indicadores de privación, frente a aquél realizado con un indicador monetario. Éste es el caso de los hogares monoparentales, para los que se reduce significativamente esta probabilidad cuando se analiza la privación frente a los ingresos equivalentes, aunque sigue siendo el tipo de hogar con mayor probabilidad de caer dentro de la pobreza.

\section{CONCLUSIONES}

El trabajo aquí desarrollado retoma el análisis de los determinantes socioeconómicos de la pobreza extrema en nuestro país a comienzos del nuevo siglo. Pensamos que los cambios acaecidos en las últimas décadas en España pueden haber producido cambios también en la caracterización y en los determinantes de las situaciones de pobreza extrema, tema de especial relevancia por referirse al conjunto más desfavorecido de la población. El análisis de los determinantes de la pobreza extrema constituye el objetivo fundamental del trabajo, el cual se ha analizado desde

\footnotetext{
${ }^{31}$ Se entiende como empeoramiento un incremento en la probabilidad de situarse en situación de pobreza extrema.
} 
dos perspectivas complementarias: por una parte, se han caracterizado los hogares pobres según éstos alcancen o no un umbral de renta, esto es, siguiendo una aproximación monetaria de la pobreza. Pero siendo conscientes de que la pobreza es un concepto multidimensional que no sólo abarca la falta de recursos económicos, se ha utilizado también un enfoque de privación, en el que la pobreza de un hogar queda determinada por la falta o carencia de un conjunto de bienes o servicios básicos. Ésta es una línea de investigación menos frecuente en la literatura española, pero en creciente auge, que pensamos puede completar la visión puramente monetaria de la pobreza. La Encuesta de Condiciones de Vida (2004), empleada en este trabajo, permite abordar estas cuestiones, tanto por la actualidad de sus datos, como por el hecho de que cuenta con un módulo específico destinado a la exclusión social de los hogares españoles.

La primera parte del estudio se ha dedicado a caracterizar la evolución experimentada en el perfil de los hogares españoles entre los años noventa y el comienzo del nuevo milenio. Los cambios más relevantes que se han producido en su estructura socioeconómica en este periodo se refieren, fundamentalmente, al mayor nivel educativo alcanzado por los sustentadores principales, a una presencia superior de hogares encabezados por mujeres, y a un cambio en la composición de los hogares, que se traduce en un importante aumento de los hogares monoparentales, así como en una disminución de los hogares numerosos.

¿Y cómo han afectado estos cambios a los hogares de muy baja renta? Si nos centramos en el estudio de los factores que afectan a la probabilidad de que un hogar tenga bajos ingresos, se observa que ciertas características sociodemográficas siguen siendo determinantes en la actualidad, aunque algunos factores han variado su signo y magnitud respecto a los años noventa. Así, parece que en 2004 el riesgo de pobreza extrema disminuye con la edad, con la diferencia de que ahora son las mujeres las que presentan una menor probabilidad de ser pobres. En relación a las dimensiones del hogar, se mantiene la precaria situación de los hogares unipersonales, reforzándose aún más la posición de debilidad de los hogares monoparentales ya apuntada en los años noventa, con el agravante de que este tipo de hogares tiene una presencia cada vez mayor, derivada de los importantes cambios que se están produciendo en nuestra sociedad, con un aumento creciente del número de disoluciones de matrimonios. Centrándonos en el ámbito educativo y laboral, de nuevo se demuestra el valor de tener mayores niveles educativos como protección frente a situaciones de pobreza, y la mayor heterogeneidad de situaciones en el caso del estatus laboral. En relación con los aspectos territoriales, se mantiene la existencia de un peor escenario para los municipios con menor densidad de población. Cabe señalar, además, el importante papel jugado por las transferencias a los hogares, sobre todo las de jubilación. Estos resultados corroboran los alcanzados por estudios similares, contrastados más recientemente a través del Panel de Hogares de la Unión Europea, como se desprende, entre otros, del trabajo de Ayala et al. (2003). Además, es importante señalar que cuando el análisis se centra en la pobreza extrema se obtienen resultados que difieren con los obtenidos cuando se es- 
tudia la pobreza en general, como es el hecho de que el sustentador principal sea mayor de 64 años, o que sea trabajador a tiempo completo. Por ello, parece justificado analizar el grupo de pobres extremos en particular, teniendo en cuenta eso sí las precauciones estadísticas necesarias, derivadas del hecho de trabajar con una muestra en muchos casos reducida.

Cuando repetimos el análisis anterior bajo un concepto de privación y analizamos la pobreza desde una perspectiva multidimensional, esto es, ampliando el concepto de pobreza y considerando otras dimensiones de la misma (acceso a bienes básicos para tener una vida digna, educación, salud, participación social, etc.), los resultados muestran algunas diferencias con respecto a la visión monetaria. A resultados similares llega el trabajo de Ayllón et al. (2007). En nuestro caso, se aprecia el mayor impacto del hecho de ser mujer en la probabilidad de que un hogar se considere privado. Todo lo contrario ocurre con los hogares monoparentales, los cuales reducen esta probabilidad bajo el enfoque de privación. Por otra parte, los hogares situados en municipios con mayor densidad de población presentan una mayor probabilidad de considerarse privados, demostrándose así que los mayores niveles de ingresos de estos hogares no tienen por qué garantizarles unos niveles menores de privación debido, probablemente, a los mayores gastos que implica el vivir en ciudades más grandes. Al estudiar la pobreza desde una perspectiva de privación, se observa que las transferencias públicas son insuficientes para garantizar la reducción de los niveles de privación que sufren los hogares beneficiarios y, por tanto, los hogares que reciben transferencias tienen una mayor probabilidad de encontrarse dentro de la pobreza.

El hecho de que exista alguna diferencia entre los resultados obtenidos para las dos aproximaciones confirma la importancia de considerar la pobreza como un concepto multidimensional. La pobreza abarca diversos aspectos de los hogares y no sólo depende de la renta. Ésta es un factor determinante, pero no es el único. Puede considerarse que un hogar con una renta por encima del umbral de pobreza tiene suficiente capacidad para acceder a los bienes y servicios que la sociedad donde vive considere oportunos. Sin embargo, esto no tiene por qué garantizar que acceda a ellos de manera efectiva. De la misma manera, puede suceder que hogares con rentas por debajo del umbral de pobreza desde una visión monetaria, puedan gozar de un acceso a determinados bienes y servicios y tener cubiertas una serie de necesidades básicas. Todo esto nos hace reflexionar sobre la necesidad de trabajar de manera conjunta con ambos tipos de indicadores, directos e indirectos, para identificar de una manera más precisa los hogares situados en una situación de pobreza extrema. Esto puede, sin duda, permitir una detección más eficaz y completa de los hogares pobres, puesto que se profundiza no sólo en las carencias monetarias de dichos hogares, sino también en sus necesidades de un conjunto de bienes y servicios básicos. Esta información puede ser de gran relevancia al proponer medidas de política económica de lucha contra la pobreza. 


\section{AGRADECIMIENTOS:}

Los autores agradecen a sus compañeros de departamento sus sugerencias y comentarios, especialmente a la profesora $D^{a}$ Pilar Martín-Guzmán. Todos los errores $u$ omisiones son responsabilidad de los autores.

\section{REFERENCIAS BIBLIOGRÁFICAS}

ATKINSON, A.B. (2003): "Multidimensional deprivation: Contrasting social welfare and counting approaches", Journal of Economic Inequality, $\mathrm{n}^{\circ}$ 1, pp. 51-65.

AYALA, L. (2005): "La monitorización de la desigualdad y la exclusión social: hacia un sistema integrado de indicadores". Documentación Social, n 137, pp. 169-192.

AYALA, L.; MARTíNEZ, R. y RUIZ-HUERTA, J. (2003): "Estrategias selectivas en las prestaciones sociales: efectos sobre la pobreza". Hacienda Pública Española. Monografía 2003, pp. 157-184.

AYALA, L. y PALACIO, J.I. (2000): "Hogares de baja renta en España: caracterización y determinantes". Revista de Economía Aplicada, nº 25 (vol. VIII), pp. 35-70.

AYLLÓN, S.; MERCADER, M. y RAMOS, X. (2007): "Caracterización de la privación y de la Pobreza en Cataluña", Revista de Economía Aplicada, nº 44, pp. 137-175.

BIBI, S. (2003): Measuring poverty in a multidimensional perspective: $A$ review of literature, Québec, Canada, Cirpée, Université Laval.

BOURGUIGNON, F. y CHACKRAVARTY, S.R. (1998): "A family of multidimensional poverty measures", Delta Document, n 98-03.

BOURGUIGNON, F. y CHACKRAVARTY, S.R. (2003): "The measurement of multidimensional poverty", Journal of Economic Inequality, $\mathrm{n}^{\circ} 1$, pp. 25-49.

CANTÓ, O.; DEL RÍO, C. y GRADÍN, C. (2000): "La situación de los estudios de desigualdad y pobreza en España" Cuadernos de Gobierno y Administración, n 2, pp. 36-88.

CANTÓ, O.; DEL RÍO, C. y GRADÍN, C. (2003): "La evolución de la pobreza estática y dinámica en España en el período 1985-1995", Hacienda Pública Española, n 167 (4/2003), pp. 87-119.

DE VOS, K. y ZAIDI, M.A. (1997): "Equivalence scales sensitivity of poverty statistics for the member status of the European Community". Review of Income and Wealth, $n^{\circ} 43$ (3), pp. $319-333$.

DEL RÍO, O. y RUIZ CASTILLO, J. (2001): "Accounting for the decline in Spanish household expenditures inequality during the 1980s", Spanish Economic Review, n 3, pp. 151-175.

DESAI, M. y SHAH, A. (1988): "An econometric approach to the measurement of poverty", Oxford Economic Papers, n 40 (3), pp. 505-22.

ENCUESTA DE CONDICIONES DE VIDA (2004): "Ficheros de usuario del primer ciclo". 2006. Disponible en: Instituto Nacional de Estadística. http://www.ine.es/jaxi/ menu.do?type=pcaxis\&path=\%2Ft25/p453\&file=inebase \&L=0 [28/10/2008].

ENCUESTA BÁSICA DE PRESUPUESTOS FAMILIARES (1990-91): "Encuesta Básica de Presupuestos Familiares". Disponible en: Instituto Nacional de Estadística. http://www.ine.es/prodyser/micro_ebpf8191.htm [28/10/2008]

EUROSTAT (2000): European social statistics. Income, poverty and social exclusion. Luxembourg. 
ESTEVE, F.; GARCÍA, A.; MUÑOZ, R.; RENES, V. y RODRÍGUEZ, G. (1998) Las condiciones de vida de la población pobre en España. Madrid: Fundación Foessa.

FOSTER, J.E.; GREER, J. y THORBECKE, E. (1984): "A class of decomposable poverty measures". Econometrica, n 52 (3), pp. 761-65.

GREENE, W. H. (1998) Análisis econométrico. Madrid: Prentice Hall Iberia, 1998, Tercera Edición.

MACK, J. y LANSLEY, S. (1985): Poor Britain. Londres: Allen Unwin.

MARCO, R. y ORTIZ, S. (2006): La medición estadística de la pobreza. Madrid. Visión Net.

MARTÍNEZ, R. y RUIZ-HUERTA, J. (2000): "Income, multiple deprivation and poverty: an empirical analysis using Spanish data", 26 IARIW General Conference, Cracovia.

MARTÍN-GUZMÁN, P.; TOLEDO, M.I.; BELLIDO, N.; LÓPEZ ORTEGA, F.J. y JANO, D. (1996): Desigualdad y pobreza en España. Estudio basado en las Encuestas de Presupuestos Familiares de 1973-74, 1980-81 y 1990-91. Madrid. Publicaciones del INE.

MARTÍN-GUZMÁN, P. y BELLIDO, N. (1994): "El equipamiento de los hogares como indicador de pobreza: un análisis basado en la EPF", Documentación Social, n 96, pp. 127-142.

PÉREZ-MAYO, J. (2003): "Measuring deprivation in Spain”, IRISS Working Paper $\mathrm{n}^{\circ}$ 200309.

RUIZ-CASTILLO, J. (1987): "La medición de la pobreza y la desigualdad en España". Estudios Económicos, $\mathrm{n}^{\circ}$ 42. Banco de España.

TOWNSEND, P. (1979): Poverty in the United Kingdom. Harmondsworth: Penguin.

ZUBIRI, I. (1985): "Una introducción a la medición de la desigualdad." Hacienda Pública Española, nº 95, pp. 291-317. 


\section{ANEXO}

\section{Cuadro 1.}

Distribución de los hogares (\%) según características del hogar y del sustentador principal, 1990 y 2004.

\begin{tabular}{|c|c|c|c|c|}
\hline & \multirow{2}{*}{ Variable } & \multirow{2}{*}{ Categorías } & \multicolumn{2}{|c|}{ Frecuencias relativas } \\
\hline & & & EBPF 1990-91 & ECV 2004 \\
\hline \multirow{15}{*}{ Sustentador principal } & \multirow{8}{*}{ Sexo-edad } & $\mathrm{H}-<30$ & $5,3 \%$ & $2,5 \%$ \\
\hline & & $\mathrm{H}-30-49$ & $34,37 \%$ & $28,32 \%$ \\
\hline & & H-50-64 & $25,84 \%$ & $19,08 \%$ \\
\hline & & $\mathrm{H}->64$ & $16,92 \%$ & $17,17 \%$ \\
\hline & & $\mathrm{M}-<30$ & $0,87 \%$ & $1,41 \%$ \\
\hline & & M-30-49 & $3,87 \%$ & $10,93 \%$ \\
\hline & & $M-50-64$ & $4,73 \%$ & $7,20 \%$ \\
\hline & & $M->64$ & $8,13 \%$ & $13,43 \%$ \\
\hline & \multirow{3}{*}{ Nivel de estudios } & $\begin{array}{l}\text { E. Primaria y E. Secunda- } \\
\text { ria de } 1^{\text {a }} \text { etapa }\end{array}$ & $78,16 \%$ & $60,58 \%$ \\
\hline & & $\begin{array}{l}\text { E. Secundaria de } \\
2^{\mathrm{a}} \text { etapa }\end{array}$ & $12,62 \%$ & $17,05 \%$ \\
\hline & & E. Superior & $9,23 \%$ & $22,37 \%$ \\
\hline & \multirow{4}{*}{ Situación laboral } & Trabaja & $59,01 \%$ & $51,49 \%$ \\
\hline & & Parado & $5,04 \%$ & $5,94 \%$ \\
\hline & & Jubilado & $33,58 \%$ & $26,12 \%$ \\
\hline & & Incapacitado & $2,37 \%$ & $16,44 \%$ \\
\hline \multirow{15}{*}{ Hogar } & \multirow{5}{*}{$\begin{array}{l}\text { Tamaño del hogar } \\
\text { ( } \mathrm{n}^{\circ} \text { de miembros) }\end{array}$} & 1 & $9,99 \%$ & $15,55 \%$ \\
\hline & & 2 & $22,30 \%$ & $27,17 \%$ \\
\hline & & 3 & $20,77 \%$ & $23,76 \%$ \\
\hline & & 4 & $24,97 \%$ & $24,65 \%$ \\
\hline & & 5 ó más de 5 & $21,97 \%$ & $8,87 \%$ \\
\hline & \multirow{7}{*}{ Tipo de hogar } & Unipersonal & $9,99 \%$ & $15,55 \%$ \\
\hline & & Pareja sin hijos & $21,88 \%$ & $20,59 \%$ \\
\hline & & Monoparental & $0,81 \%$ & $2,03 \%$ \\
\hline & & Pareja con 1 hijo & $8,64 \%$ & $10,32 \%$ \\
\hline & & Pareja con 2 hijos & $12,04 \%$ & $11,93 \%$ \\
\hline & & $\begin{array}{l}\text { Pareja con más de } 2 \text { hijos } \\
\text { Otros hogares sin hijos }\end{array}$ & $\begin{array}{c}4,93 \% \\
23,62 \%\end{array}$ & $\begin{array}{c}1,75 \% \\
20,48 \%\end{array}$ \\
\hline & & Otros hogares & $18,09 \%$ & $17,35 \%$ \\
\hline & \multirow{3}{*}{ Densidad de población } & Muy poblada & $51,31 \%$ & $53,46 \%$ \\
\hline & & Densidad media & $22,49 \%$ & $19,73 \%$ \\
\hline & & Poco poblada & $26,19 \%$ & $26,81 \%$ \\
\hline
\end{tabular}

Fuente: Elaboración propia a partir de ECV (2004) y EBPF (1990-91). 


\section{Cuadro 2.}

Índices de Foster, Greer y Thorbecke, según características del hogar y del sustentador principal, 2004.

\begin{tabular}{|c|c|c|c|c|c|}
\hline & Variable & Categorías & FGT (0) & FGT (1) & FGT (2) \\
\hline \multirow{18}{*}{ Sustentador principal } & \multirow{8}{*}{ Sexo-edad } & $\mathrm{H}-<30$ & 6,86 & 4,20 & 3,11 \\
\hline & & $\mathrm{H}-30-49$ & 4,12 & 2,43 & 1,94 \\
\hline & & $\mathrm{H}-50-64$ & 3,69 & 1,95 & 1,53 \\
\hline & & $\mathrm{H}->64$ & 1,54 & 0,62 & 0,41 \\
\hline & & $M-<30$ & 6,10 & 3,15 & 2,42 \\
\hline & & M-30-49 & 4,91 & 2,39 & 1,57 \\
\hline & & M-50-64 & 2,84 & 1,50 & 1,06 \\
\hline & & $M->64$ & 2,47 & 1,01 & 0,73 \\
\hline & \multirow{4}{*}{ Nivel de estudios } & E. Primaria & 3,79 & 1,88 & 1,38 \\
\hline & & E. Secundaria de $1^{\mathrm{a}}$ etapa & 3,87 & 2,21 & 1,71 \\
\hline & & E. Secundaria de $2^{\mathrm{a}}$ etapa & 4,58 & 2,76 & 2,24 \\
\hline & & E. Superior & 2,01 & 1,07 & 0,78 \\
\hline & \multirow{6}{*}{ Situación laboral } & Trabaja a tiempo completo & 2,94 & 1,73 & 1,37 \\
\hline & & Trabaja a tiempo parcial & 6,26 & 2,84 & 1,75 \\
\hline & & Parado & 14,39 & 8,20 & 6,44 \\
\hline & & Jubilado & 1,59 & 0,59 & 0,37 \\
\hline & & Incapacitado & 3,72 & 1,42 & 0,82 \\
\hline & & Otra inactividad & 5,18 & 2,31 & 1,61 \\
\hline \multirow{18}{*}{ Hogar } & \multirow{7}{*}{$\begin{array}{l}\text { Tamaño del hogar } \\
\left(\mathrm{n}^{\circ} \text { de miembros }\right)\end{array}$} & 1 & 5,78 & 3,59 & 2,95 \\
\hline & & 2 & 2,75 & 1,54 & 1,22 \\
\hline & & 3 & 2,92 & 1,30 & 0,87 \\
\hline & & 4 & 3,39 & 1,62 & 1,10 \\
\hline & & 5 & 2,30 & 1,04 & 0,75 \\
\hline & & 6 & 2,93 & 1,29 & 0,74 \\
\hline & & Más de 6 & 10,75 & 4,01 & 2,50 \\
\hline & \multirow{8}{*}{ Tipo de hogar } & Unipersonal & 5,78 & 3,59 & 2,95 \\
\hline & & Pareja sin hijos & 2,32 & 1,30 & 1,02 \\
\hline & & Monoparental & 14,98 & 7,14 & 4,86 \\
\hline & & Pareja con 1 hijo & 3,42 & 1,61 & 1,14 \\
\hline & & Pareja con 2 hijos & 4,33 & 2,20 & 1,56 \\
\hline & & Pareja con más de 2 hijos & 5,91 & 2,47 & 1,57 \\
\hline & & Otros hogares sin hijos & 1,57 & 0,64 & 0,41 \\
\hline & & Otros hogares & 2,49 & 1,20 & 0,87 \\
\hline & \multirow{3}{*}{$\begin{array}{l}\text { Densidad de pobla- } \\
\text { ción }\end{array}$} & Muy poblada & 2,85 & 1,65 & 1,29 \\
\hline & & Densidad media & 3,95 & 1,93 & 1,39 \\
\hline & & Poco poblada & 4,26 & 2,05 & 1,48 \\
\hline
\end{tabular}

Fuente: Elaboración propia a partir de ECV, 2004. 


\section{Cuadro 3.}

Asociación: Test estadístico V-Cramer.

\begin{tabular}{|c|c|c|}
\hline & Estatus laboral & Tipo de hogar \\
\hline Receptor de transferencias & 0,5897 & \\
Receptor de salarios & 0,6192 & \\
Tamaño del hogar & & 0,617 \\
\hline
\end{tabular}

Fuente: Elaboración propia a partir de ECV (2004).

Nota: Todas las asociaciones son estadísticamente significativas al 99,99\%. La formulación del coeficiente $V$ de Cramer es la siguiente: $V=\sqrt{\frac{\chi^{2}}{n(k-1)}}$, donde $\chi^{2}$ es el valor del estadístico Chi-cuadrado de independencia entre las dos variables analizadas, $n$ es el tamaño muestral y $k$ en el valor mínimo entre el número de categorías de cada una de las dos variables analizadas. El rango del coeficiente $V$ Cramer está entre 0 y 1 , siendo 0 el valor que se obtiene ante ausencia de asociación y 1 el valor que se obtiene ante una situación de asociación perfecta. 


\section{Cuadro 4.}

Determinantes socioeconómicos de la pobreza extrema en España en 2004 desde una aproximación monetaria.

\begin{tabular}{|c|c|c|c|c|c|c|c|c|c|}
\hline & & Modelo 1 & pvalor & Modelo 2 & pvalor & Modelo 3 & pvalor & Modelo 4 & pvalor \\
\hline \multirow{16}{*}{ 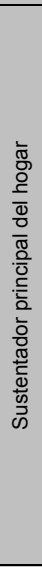 } & Hombre, $<30$ años & 0,16395 & 0,000 & 0,16698 & 0,000 & 0,16446 & 0,000 & 0,18355 & 0,000 \\
\hline & Hombre, $30-49$ años & 0,08859 & 0,000 & 0,07366 & 0,000 & 0,10007 & 0,000 & 0,08940 & 0,000 \\
\hline & Hombre, 50-64 años & 0,10476 & 0,000 & 0,07208 & 0,000 & 0,10053 & 0,000 & 0,07318 & 0,000 \\
\hline & Hombre, más de 64 años & 0,04845 & 0,001 & 0,00747 & 0,304 & 0,04266 & 0,004 & 0,00381 & 0,589 \\
\hline & Mujer, $<30$ años & 0,12558 & 0,000 & 0,16538 & 0,000 & 0,14019 & 0,000 & 0,19491 & 0,000 \\
\hline & Mujer, 30-49 años & 0,06936 & 0,000 & 0,09030 & 0,000 & 0,10097 & 0,000 & 0,13235 & 0,000 \\
\hline & Mujer, 50-64 años & 0,03008 & 0,004 & 0,03387 & 0,001 & 0,03505 & 0,001 & 0,04329 & 0,000 \\
\hline & Estudios Secundarios, $1^{\mathrm{a}} \mathrm{e}$ & $-0,01066$ & 0,002 & $-0,00993$ & 0,001 & $-0,01021$ & 0,005 & $-0,00947$ & 0,003 \\
\hline & Estudios Secundarios, $2^{\mathrm{a}} \mathrm{e}$ & $-0,00710$ & 0,090 & $-0,00827$ & 0,019 & $-0,00641$ & 0,153 & $-0,00755$ & 0,046 \\
\hline & Educación Superior & $-0,02030$ & 0,000 & $-0,01848$ & 0,000 & $-0,02117$ & 0,000 & $-0,01900$ & 0,000 \\
\hline & Trabaja a tiempo completo & 0,00126 & 0,847 & & & 0,00196 & 0,772 & & \\
\hline & Trabaja a tiempo parcial & 0,03663 & 0,009 & & & 0,03950 & 0,007 & & \\
\hline & Parado & 0,07735 & 0,000 & & & 0,08719 & 0,000 & & \\
\hline & Incapacitado & 0,00447 & 0,669 & & & 0,00575 & 0,600 & & \\
\hline & Labores del hogar & 0,05579 & 0,000 & & & 0,05648 & 0,000 & & \\
\hline & Otra inactividad & 0,06857 & 0,000 & & & 0,07130 & 0,000 & & \\
\hline \multirow{15}{*}{ 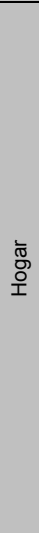 } & Recibe transferencias públicas & & & $-0,01378$ & 0,000 & & & $-0,01183$ & 0,001 \\
\hline & Perceptor de salarios & & & $-0,05014$ & 0,000 & & & $-0,05417$ & 0,000 \\
\hline & Pareja sin hijos & $-0,01996$ & 0,000 & $-0,01489$ & 0,000 & & & & \\
\hline & Monoparental & 0,03200 & 0,003 & 0,03413 & 0,001 & & & & \\
\hline & Pareja, 1hijo & $-0,01794$ & 0,000 & $-0,01043$ & 0,012 & & & & \\
\hline & Pareja, 2hijos & $-0,01472$ & 0,001 & $-0,00841$ & 0,048 & & & & \\
\hline & Pareja, +2hijos & $-0,01191$ & 0,070 & $-0,00305$ & 0,674 & & & & \\
\hline & Hogares sin hijos & $-0,02673$ & 0,000 & $-0,01889$ & 0,000 & & & & \\
\hline & Otros hogares & $-0,02287$ & 0,000 & $-0,01476$ & 0,000 & & & & \\
\hline & Tamaño hogar: 2 & & & & & $-0,01846$ & 0,000 & $-0,01305$ & 0,001 \\
\hline & Tamaño hogar: 3 & & & & & $-0,02213$ & 0,000 & $-0,01318$ & 0,000 \\
\hline & Tamaño hogar: 4 & & & & & $-0,02222$ & 0,000 & $-0,01373$ & 0,001 \\
\hline & Tamaño hogar: 5 & & & & & $-0,02361$ & 0,000 & $-0,01629$ & 0,000 \\
\hline & Tamaño hogar: 6 & & & & & $-0,02016$ & 0,001 & $-0,01165$ & 0,097 \\
\hline & Tamaño hogar: más de 6 & & & & & $-0,01751$ & 0,089 & $-0,00763$ & 0,523 \\
\hline \multirow{3}{*}{$\stackrel{\widetilde{N}}{\mathrm{~N}}$} & Densidad de población media & 0,00681 & 0,090 & 0,00620 & 0,089 & 0,00763 & 0,066 & 0,00681 & 0,069 \\
\hline & Densidad de población baja & 0,00902 & 0,013 & 0,00593 & 0,060 & 0,00980 & 0,009 & 0,00636 & 0,050 \\
\hline & $\begin{array}{c}\text { Número de observaciones } \\
\text { Wald } \text { chi }^{2} \\
\text { Prob }>\text { chi }^{2} \\
\text { Pseudo } \mathrm{R}^{2} \\
\% \text { de predicciones correctas } \\
\% \text { de predicciones correctas }{ }^{*} \text { para pobreza }=0 \\
\text { pobreza }=1\end{array}$ & $\begin{array}{c}13.180 \\
271,16 \\
0,000 \\
0,113 \\
66,28 \% \\
66,80 \% \\
\end{array}$ & & $\begin{array}{c}13.180 \\
352,91 \\
0,000 \\
0,1568 \\
73,99 \% \\
71,07 \% \\
\end{array}$ & & $\begin{array}{c}13.180 \\
238,41 \\
0,000 \\
0,0957 \\
64,23 \% \\
69,30 \% \\
\end{array}$ & & $\begin{array}{c}13.180 \\
340,55 \\
0,000 \\
0,1414 \\
74,82 \% \\
71,05 \% \\
\end{array}$ & \\
\hline
\end{tabular}

* Punto de corte: $3,28 \%$.

Nota: Categorías de referencia (respectivamente): Mujer de más de 64 años, con nivel de estudios inferior a Secundaria, jubilada, no recibe transferencias públicas ni salarios, que forma un hogar unipersonal, vive en una zona con densidad de población alta.

Fuente: Elaboración propia a partir de ECV, 2004. 


\section{Cuadro 5.}

Determinantes socioeconómicos de la pobreza extrema en España en 2004 desde una aproximación de privación.

\begin{tabular}{|c|c|c|c|c|c|c|c|c|c|}
\hline & & Modelo 1 & pvalor & Modelo 2 & pvalor & Modelo 3 & pvalor & Modelo 4 & pvalor \\
\hline \multirow{16}{*}{ 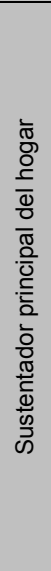 } & Hombre, $<30$ años & 0,08601 & 0,000 & 0,14629 & 0,000 & 0,07166 & 0,000 & 0,13370 & 0,000 \\
\hline & Hombre, 30-49 años & 0,03938 & 0,000 & 0,06021 & 0,000 & 0,03621 & 0,000 & 0,05962 & 0,000 \\
\hline & Hombre, 50-64 años & 0,01313 & 0,095 & 0,03018 & 0,001 & 0,00985 & 0,212 & 0,02952 & 0,002 \\
\hline & Hombre, más de 64 años & 0,00466 & 0,517 & 0,00306 & 0,654 & $-0,00143$ & 0,829 & $-0,00275$ & 0,662 \\
\hline & Mujer, $<30$ años & 0,22744 & 0,000 & 0,33727 & 0,000 & 0,22039 & 0,000 & 0,34023 & 0,000 \\
\hline & Mujer, 30-49 años & 0,06077 & 0,000 & 0,11313 & 0,000 & 0,07095 & 0,000 & 0,13247 & 0,000 \\
\hline & Mujer, 50-64 años & 0,02109 & 0,020 & 0,04361 & 0,000 & 0,02579 & 0,008 & 0,05426 & 0,000 \\
\hline & Estudios Secundarios, $1^{\mathrm{a}} \mathrm{e}$ & $-0,00881$ & 0,006 & $-0,00946$ & 0,004 & $-0,00930$ & 0,005 & $-0,00997$ & 0,003 \\
\hline & Estudios Secundarios, $2^{\mathrm{a}} \mathrm{e}$ & $-0,01739$ & 0,000 & $-0,01850$ & 0,000 & $-0,01847$ & 0,000 & $-0,01938$ & 0,000 \\
\hline & Educación Superior & $-0,02148$ & 0,000 & $-0,02288$ & 0,000 & $-0,02330$ & 0,000 & $-0,02449$ & 0,000 \\
\hline & Trabaja a tiempo completo & $-0,01003$ & 0,058 & & & $-0,00931$ & 0,090 & & \\
\hline & Trabaja a tiempo parcial & 0,01533 & 0,123 & & & 0,01670 & 0,101 & & \\
\hline & Parado & 0,03845 & 0,000 & & & 0,04316 & 0,000 & & \\
\hline & Incapacitado & 0,02211 & 0,020 & & & 0,02390 & 0,016 & & \\
\hline & Labores del hogar & $-0,00293$ & 0,615 & & & $-0,00394$ & 0,504 & & \\
\hline & Otra inactividad & 0,01745 & 0,029 & & & 0,01915 & 0,022 & & \\
\hline \multirow{15}{*}{ 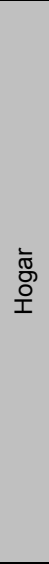 } & Recibe transferencias públicas & & & 0,01094 & 0,001 & & & 0,01262 & 0,000 \\
\hline & Perceptor de salarios & & & $-0,01685$ & 0,000 & & & $-0,01740$ & 0,000 \\
\hline & Pareja sin hijos & $-0,01695$ & 0,000 & $-0,01784$ & 0,000 & & & & \\
\hline & Monoparental & 0,02012 & 0,025 & 0,01636 & 0,068 & & & & \\
\hline & Pareja, 1hijo & $-0,00726$ & 0,117 & $-0,00812$ & 0,095 & & & & \\
\hline & Pareja, 2hijos & $-0,01098$ & 0,017 & $-0,01158$ & 0,017 & & & & \\
\hline & Pareja, +2hijos & $-0,00102$ & 0,901 & $-0,00212$ & 0,809 & & & & \\
\hline & Hogares sin hijos & $-0,00897$ & 0,047 & $-0,00815$ & 0,097 & & & & \\
\hline & Otros hogares & $-0,00065$ & 0,878 & $-0,00038$ & 0,933 & & & & \\
\hline & Tamaño del hogar: 2 & & & & & $-0,01013$ & 0,014 & $-0,01082$ & 0,011 \\
\hline & Tamaño del hogar: 3 & & & & & $-0,00659$ & 0,124 & $-0,00709$ & 0,124 \\
\hline & Tamaño del hogar: 4 & & & & & $-0,01063$ & 0,019 & $-0,01079$ & 0,028 \\
\hline & Tamaño del hogar: 5 & & & & & 0,00026 & 0,966 & 0,00008 & 0,990 \\
\hline & Tamaño del hogar: 6 & & & & & 0,00289 & 0,748 & 0,00277 & 0,772 \\
\hline & Tamaño del hogar: más de 7 & & & & & $-0,01244$ & 0,125 & $-0,01320$ & 0,102 \\
\hline \multirow{8}{*}{$\begin{array}{l}\text { ర్ } \\
\text { 음 }\end{array}$} & Densidad de población media & $-0,00155$ & 0,643 & $-0,00202$ & 0,557 & $-0,00161$ & 0,641 & $-0,00222$ & 0,531 \\
\hline & Densidad de población baja & $-0,00841$ & 0,003 & $-0,00960$ & 0,001 & $-0,00920$ & 0,001 & $-0,01056$ & 0,000 \\
\hline & Número de observaciones & 13.180 & & 13.180 & & 13.180 & & 13.180 & \\
\hline & Wald chi ${ }^{2}$ & 290,83 & & 241,86 & & 263,08 & & 202,99 & \\
\hline & Prob $>\mathrm{chi}^{2}$ & 0,000 & & 0,000 & & 0,000 & & 0,000 & \\
\hline & Pseudo $\mathrm{R}^{2}$ & 0,129 & & 0,1126 & & 0,1167 & & 0,1008 & \\
\hline & $\begin{array}{c}\% \text { de predicciones correctas* } \\
\text { para pobreza }=0\end{array}$ & $76,67 \%$ & & $72,00 \%$ & & $72,28 \%$ & & $71,66 \%$ & \\
\hline & $\begin{array}{c}\% \text { de predicciones correctas } \\
\text { para pobreza }=1\end{array}$ & $48,47 \%$ & & $54,58 \%$ & & $47,37 \%$ & & $54,14 \%$ & \\
\hline
\end{tabular}

* Punto de corte: $3,3 \%$.

Nota: Categorías de referencia (respectivamente): Mujer de más de 64 años, con nivel de estudios inferior a Secundaria, jubilada, no recibe transferencias públicas ni salarios, que forma un hogar unipersonal, vive en una zona con densidad de población alta.

Fuente: Elaboración propia a partir de ECV, 2004. 
